\title{
Auditory Dysfunction in Aging: Prospects for Stem Cell Therapy
}

\author{
Henrique F. Pauna1,2, Maria Stella A. Amaral1, Steven K. Juhn',3, Walter C. Low ${ }^{4,5}$, \\ Miguel A. Hyppolito ${ }^{1}$
}

\author{
${ }^{1}$ Department of Ophthalmology, Otorhinolaryngology and Head and Neck Surgery, Ribeirão Preto Medical School, University of \\ São Paulo, Ribeirão Preto, Brazil \\ ${ }^{2}$ Department of Otolaryngology—Head and Neck Surgery, University of Minnesota, Minneapolis, USA \\ ${ }^{3}$ Auditory Biochemistry Laboratory, University of Minnesota Medical School, Minneapolis, USA \\ ${ }^{4}$ Stem Cell Institute, University of Minnesota, Minneapolis, USA \\ ${ }^{5}$ Department of Neurosurgery, University of Minnesota, Minneapolis, USA \\ Email: h_pauna@hotmail.com
}

How to cite this paper: Pauna, H.F., Amaral, M.S.A., Juhn, S.K., Low, W.C. and Hyppolito, M.A. (2019) Auditory Dysfunction in Aging: Prospects for Stem Cell Therapy. Advances in Bioscience and Biotechnology, 10, 13-31.

https://doi.org/10.4236/abb.2019.102002

Received: February 16, 2019

Accepted: February 25, 2019

Published: February 28, 2019

Copyright $\odot 2019$ by author(s) and Scientific Research Publishing Inc. This work is licensed under the Creative Commons Attribution International License (CC BY 4.0).

http://creativecommons.org/licenses/by/4.0/

\begin{abstract}
Age-related hearing loss is the most common cause of adult auditory dysfunction. It is characterized by bilateral, progressive auditory deterioration associated with the aging process. There currently are limited options for the treatment as hearing aids or cochlear implants. To establish novel strategies for the treatment of this entity, it is crucial to elucidate the mechanisms of age-related hearing loss. Its etiology is believed to be multifactorial including both intrinsic and extrinsic factors. Oxidative damage, as seen in other aging organs systems, may play an essential role in the pathogenesis of the age-related hearing loss. Studies on animal models and human temporal bones have indicated a close relationship between degeneration of the cochlear lateral wall and hearing loss. Additional therapies that may prove beneficial in the treatment of age-related hearing loss include stem cell therapy, which we intend to review in this manuscript.
\end{abstract}

\section{Keywords}

Aging, Presbycusis, Age-Related Hearing Loss, Stem Cell, Homeostasis

\section{Introduction}

Most multicellular organisms exhibit physiological and behavioral decline with aging. Within the auditory system, this decline is manifested as presbycusis or age-related hearing loss. Presbycusis is characterized by gradual, progressive, bilateral sensorineural hearing loss (SNHL) with associated impairment of word recognition. 
Among elderly humans, approximately $15 \%$ of the population suffers from sensorimotor disturbances without other concomitant neurological disorders, such as dementia [1] [2]. Hearing is an essential part of human communication and auditory dysfunction can seriously affect the quality of life in the aging population. Severe histopathological abnormalities caused by biological aging are observed in the ears of elderly patients, such as cell loss, tissue degeneration, and alterations in structure. The degree and type of biological changes that accompany aging can also be strongly influenced by genetic factors which may predispose individuals to develop certain types of presbycusis.

Hearing loss affects about 278 million people around the world, according to the World Health Organization (WHO) [3]. With the forecasted growth of demographics within the United States over the next two decades, it is estimated that by 2025 approximately 24.5 million American will be affected by presbycusis [4]. Presbycusis refers to the gradual loss of hearing with various types of auditory system dysfunctions that accompany aging. Approximately $35 \%$ of adults aged 65 years and over have been reported to have presbycusis. Nearly $50 \%$ of people aged 75 years and up to $80 \%$ of individuals over the age of 85 years are reported to have significant ARHL [1] [4]-[10]. Hearing loss in the elderly population is associated with decreased quality of life with social isolation and dependence, increased prevalence of symptoms of depression, and increased overall mortality through falls and accidents [1].

Several pathological characteristics have been identified, namely sensory, neural, atrophy of stria vascularis, and conductive system of sound transmission. The first type, sensory presbycusis, is characterized by slow, progressive, bilateral steep down-sloping high frequency SNHL which is attributed to loss of hair cells, particularly in the basal turn. The second type, neural presbycusis, demonstrates a loss of spiral ganglion cells and poor word discrimination in the presence of stable pure-tone thresholds. The third type, metabolic presbycusis, is associated with hearing loss characterized by with a flat pure-tone audiometric threshold which is attributed to atrophy of the stria vascularis. Finally, mechanical or cochlear conductive presbycusis is characterized by a gradually decreasing linear distribution pattern of threshold shift and presumed to be associate with stiffening of the basilar membrane, although no pathological correlate has been identified [11]. Sensorineural presbycusis is a combination of sensory and neural elements characterized by marked degeneration of hair cells and nerves. Chronic exposure to environmental and emotional stress as well as noise exposure or ototoxic drug injury is believed to contribute to ARHL. The majority of SNHL involves progressive sensorineural cochlear pathology, most notably in the basal end of the cochlea which results in loss of high frequency hearing. Recently, the importance of spiral ligament and stria vascularis in the lateral wall has also been emphasized.

\section{Causes of Presbycusis}

Several genetic and environmental factors may contribute to the hearing loss, 
such as mutations, viral infections, autoimmune disorders, chronic noise exposure, degenerative processes, ototoxic drugs, and aging [3] [12]. The aging process associates with increased DNA damage, altered gene expression and protein function, disruption of cell matrix and organelles, disrupted metabolism, and oxidative stress [13]. Among these, oxidative stress is perhaps the most fundamental cause of age-related pathology in the biological aging of cells and may be an important intrinsic factor in presbycusis. Oxidative stress is caused by accumulation of mitochondrial DNA mutations and/or deletions (or reduced mitochondrial DNA gene expression), leading to a mitochondrial dysfunction in maintain the homeostatic level of free radicals [9] [14]. Falah et al. found a total of 113 sequence variants in mitochondrial DNA in $100 \%$ of their presbycusis patients and supported the idea of the role of mitochondria in the intracellular mechanism underlying presbycusis development. Moreover, these variants may act as potential diagnostic markers for individuals at a high risk of developing presbycusis [15].

Principally implicated as a mediator of oxidative stress, inflammatory and infection-related damage in the central nervous system (CNS) and other tissues, is the presence of increased concentrations of free radicals such as reactive oxygen species (ROS) and reactive nitrogen species (RNS). ROS is comprised of superoxide free-radicals, hydrogen peroxides, and hydroxyl radicals. The main contributor to RNS is the gaseous transmitter nitric oxide (NO). NO and its oxidation product, such as peroxynitrite, has been shown to be a potent cellular mutagens and cytotoxic agents which may cause accumulated damage to normal cells [15] [16]. The increased release of NO may cause pathological conditions of the stria vascularis. ROS may contribute to presbycusis by damaging metabolically active tissues in the inner ear (e.g. stria vascularis), but also be involved in the accumulation of free radicals, damaging the mitochondrial DNA, and inactivating regulatory proteins by ROS and apoptosis.

We have observed inducible nitric oxide synthase (iNOS) immune-reactivity in the stria vascularis of aged animals while no iNOS expression was detected in young rats [17]. We also cultured marginal cells of the stria vascularis and exposed to NO by treating with the NO donor, sodium nitroprusside (SNP), and an elevation of intracellular calcium was observed. This may be related to the NO induced cellular apoptosis reported in other cells [17].

Another aspect of the aging process can be represented by decreased ability of the body to defend itself against environmental insults. Inner ear and its associated structures sustain damage throughout life like any part of the human body. Thus, it is important to have effective defense mechanisms against those damages. Heat shock proteins (HSPs) are a major component of the defensive mechanisms. HSPs are stress proteins that are involved in protecting cells from a variety of stress by binding to denatured proteins and assisting in proper folding. It has been reported that oxidative stress can induce the expression of HSPs, and HSP pre-treatment increases the protection of cells from subjacent oxidative 
stress [18] [19] [20].

Therefore, if the level of HSPs decreases with aging, it will indirectly accelerate age-related changes by exposing cells to various cellular stresses including oxidative stress. It has been reported that HSP 70 mRNA level decreases with aging [21] [22]. A disruption of inner ear homeostasis by exogenous factors such as ototoxic agents (aminoglycosides antibiotics), noise exposure, smoking, high alcohol consumption, and stress may also lead to presbycusis [23]. The ototoxic effects of aminoglycosides are destruction of hair cells and inhibition of potassium secretion in strial marginal cells. Noise exposure has been demonstrated to destroy auditory hair cells, especially outer hair cells, contribute to collapse of the organ of Corti, and impair cochlear circulation [10]. Cigarette smoking have been associated with an increased odds ratio for the development of ARHL [24]. High ethanol consumption has been associated with a slightly increased likelihood of the development of ARHL [25]. Stress hormones have been reported to have local and systemic effects on hearing by exerting significant effects on the delicate homeostatic mechanism of inner ear fluid and function of the inner ear. Other late-emerging exogenous factors such as failure of the immune system, onset of autoimmune disease, or hypoxia due to vascular insufficiency may also contribute to presbycusis.

The large individual variability in the age of onset and severity of certain types of ARHL, suggest the involvement of a genetic mechanism in presbycusis. It has been suggested that strial presbycusis is likely to have a genetic etiology because of clinical impressions that the disorder is prevalent in certain families. Animal models have been developed using C57BL mice that show progressive auditory decline with age resembling certain types of hereditary hearing loss in humans [26] [27]. Thus, it is conceivable that presbycusis may be due to a genetic predisposition for the factors that are associated with sensorineural and other types of ARHL. Future research should be directed to explore basic mechanisms of the aging processes in general as well as specific functional and clinical entities.

\section{Mechanisms of Age-Related Hearing Loss}

The normal function of the inner ear occurs within specialized hair cells by converting mechanical stimuli into electrical energy. It is well established that proper control of ionic homeostasis in the inner ear fluids is essential for normal function of the inner ear. The inner ear fluids have been reported to maintain a unique composition by several mechanisms, namely, ionic pumps, constant blood supply, and blood labyrinth barriers [28].

The sound vibration of the tympanic membrane is propagated through mechanical motion of the middle ear ossicles. Basilar membrane vibration agitates hair cells of the organ of Corti, causing them to initiate impulses. Sound waves cause the deflection of stereocilia of the hair cells, resulting in the opening of transduction channels near the tips of the stereocilia. Potassium ions move down the concentration gradient from the endolymph into the hair cells, depolarizing 
their membrane potentials. Depolarization triggers the release of neurotransmitter, glutamate that activates an action potential down the acoustic nerve, which relays to the brain. The hair cells are repolarized when potassium ions leave the hair cells through the potassium channels. Then, the potassium ions diffuse into the perilymph to the stria vascularis through gap junctions formed by connexins, then secreted back into the endolymph via $\mathrm{Na}^{+}-\mathrm{K}^{+}$-ATPase channels, thereby resetting the mechanoelectrical transduction system. Therefore, high potassium levels in the endolymph are essential for the auditory transduction process and are maintained through homeostasis.

A number of histopathologic changes have been identified from temporal bone studies in association with presbycusis. Atrophy of stria vascularis is a common pathological finding in aged human temporal bones and has been known as strial presbycusis. Marginal cells of the stria vascularis have been known to be more severely affected by aging, and atrophic changes in the spiral ligament are recognized as an acellular zone. Ichimiya et al. [29] observed ageassociated disorganization of the organ of Corti, decrease in the number of spiral ganglion cells, and atrophy of stria vascularis. This is evident by the density of connexins 26 staining reduction in the murine lateral wall of the C57BL/ 6 type mice. $\mathrm{Na}^{+}-\mathrm{K}^{+}$-ATPase immunolabeling was increased in the spiral ligament, whereas its average density was not significantly altered in the stria vascularis. Their data correlate with previous findings [30] of decreased endocochlear potential and endolymphatic potassium concentration with age found in gerbils. The decreased expression of connexins with aging is observed more frequently outside the ear, such as atrophic endothelium, brain astrocytes, and gap junctions expressed by various type of cells [31].

A study by Wu and Marcus [32] concurs with the Ichimiya study such that the spiral ligament could be among the regions responsible for cochlear malfunction with aging. The first study shows the ABR response thresholds from 6-week-old mice were significantly lower than those of 6 month or 1-year-old mice. Additionally, Sha et al. [33] observed a significant threshold shift in ABR occurring at 3 months of age at $4000 \mathrm{~Hz}$ without apparent hair cell loss in aged models of CBA/J mice; at 20 - 26 months, threshold shifts at 12 and $24 \mathrm{kHz}$ and accompanying hair cell loss at the basal turn of the cochlea; and degeneration of spiral ganglion cells by 18 months in all regions of the cochlea. Altschuler et al. [27] found moderate to large loss of outer and inner hair cell across all the cochlear turns and a significant increased ABR threshold shifts at 4, 12, 24, and $48 \mathrm{kHz}$ using UM-HET4 aged mice (27 - 29 months of age).

\subsection{Hair Cells and Organ of Corti}

Normal auditory function requires the transduction of mechanical energy (in the form of vibration of the basilar membrane and deflection of hair cell stereocilia) into electrical energy (change in the hair cell membrane potentials leading to neurotransmitter release and propagation of an action potential) in order to 
propagation the signal through the peripheral and central auditory pathway. Sensory hair cell, spiral ganglion, and auditory nerve fiber loss have been identified in association with ARHL [34]-[41].

Loss of hair cells is one of the most common findings in histopathological studies [33] [42] [43] [44]. Hair cell loss is limited to the early stages of hearing loss and almost all the process, over the time, result in loss of supporting cells in the auditory epithelium, followed by cochlear nerve and spiral ganglion neuronal degeneration [45] [46]. Kusunoki et al. found a significant correlation between the loss of both inner and outer hair cells and aging in the basal turn of the cochlea in human temporal bones [47]. Altschuler et al. found a greater outer hair cells loss in aged UM-HET4 mices (22 - 24 months) [27]. Furthermore, stereocilia disarray and absence has been observed within inner and outer hair cells of the organ of Corti in aged animals [37].

The regenerative capability of hair cells is lost in the early stages in development. Because hair cells do not usually regenerate post development, investigating the ways to regenerate hair cells in adults holds a great therapeutic potential in treating people with hearing loss [13]. Many studies have reported factors that improve proliferation and regeneration of mammalian hair cells, including: inhibition of p27 ${ }^{\text {Kip1 }}$ [48] [49], retinoblastoma ( $\left.\mathrm{Rb}\right)$ [50] [51], retinoblastoma-like protein 2 (Rbl2) [52], p21 $1^{\mathrm{Cip} 1}$ and p19 $9^{\text {Ink4d }}$ [53] and overexpression of beta-catenin [54] and protein atonal homolog 1 (Atoh 1) [55]. Interestingly, Xia et al. found a decrease in $\mathrm{Wnt} / \beta$-catenin signaling in auditory cortex in both naturally aging and D-galactose-mimetic aging rats. They showed that the expression of Bmil was reduced and the expression of its downstream genes, $\mathrm{p} 16^{\mathrm{INK4a}}, \mathrm{p} 19^{\mathrm{Arf}}$, and p53 were increased in the auditory cortex both groups. Their results may point that decreased $\mathrm{Wnt} / \beta$-catenin signaling might participate in the pathogenesis of central presbycusis through modulating the expression of Bmil, and also might be used as a potential therapeutic target against presbycusis [56].

\subsection{Spiral Ligament and Stria Vascularis}

In addition to the age-related degeneration of the hair cells and the auditory pathway, degeneration of the cochlear lateral wall is considered to be another important mechanism of presbycusis [29] [57] [58]. Lateral wall structures are crucial in the maintenance of endolymphatic potassium levels, endocochlear potentials, and ion homeostasis within the cochlea. Studies with aging animals showed an increased apoptosis and atrophy within the lateral wall [59] [60].

Aging process is related to many molecular, biochemical and physiological changes. Immunohistochemical analysis of C57BL/6J mouse temporal bones demonstrated vascular endothelial growth factor (VEGF) expression in the stria vascularis, spiral ligament, and spiral ganglion cells of young mice [61]. However, aged mice demonstrated a significant decrease in immunoreactivity in all aforementioned areas. Altered vascular characteristics, such as reduced red blood cell velocity and vascular plasticity, increased vascular permeability may 
contribute to this aging process [62]. Therefore, vascular occlusion or ischemia associated with aging may play a role in ARHL. Kusunoki et al. showed a significant correlation between aging and missing fibrocytes in the spiral ligament of human temporal bones, especially at the lower turns. They also showed a significant correlation between the decreased area of the stria vascularis and aging [47]. Using an animal model, Yang et al. showed a dramatically decreased expression of potassium channel, by means of fluorescence immunohistochemistry, in the stria vascularis of a group of 12-month-old C57BL/6 mices [26].

\subsection{Nerves in the Auditory System}

The electrical signaling to and from the brain is affected by aging [13]. The impairment in this electrical signaling may cause morphological changes in the auditory brainstem, especially in the cochlear nucleus [63]. The cochlear nucleus is located on the lateral side of the mammalian brainstem representing the first relay station for acoustic-derived neuronal input from the inner ear. Spiral ganglion neurons synapse with auditory neurons in the cochlear nucleus to relay auditory information to higher levels of the brain.

Sha et al., observed a degeneration of spiral ganglion in CBA/J aged animals (up to 23 - 25 months of age), and elevation of ABR thresholds at $4 \mathrm{kHz}$ as well [33], and so Akil et al. using C57BL/6J mices up to 15 months of age [64]. Tang et al., comparing young adults ( 2 - 3 months of age) of CBA/CaJ mouse to aged animals (24 - 32 months of age) found a decreased spiral ganglion neurons density along with aging in all the cochlear turns, but it declined at most in the basal turn of the cochlea [65]. Lastly, Qian et al. found temporal lobe atrophy relative to brain atrophy, both correlated to hearing level changes. Their multiple linear regression analysis of age, high frequency pure-tone averages, and temporal lobe atrophy demonstrated a significant interaction between audiological tests and temporal lobe atrophy, suggesting that age itself could not be attributed to temporal lobe atrophy $[1]$.

\section{The Use of Stem Cells}

A successful treatment of severe to profound SNHL can be achieved by using hearing aids or other implantable devices, such as cochlear implants, and depends on activation of auditory nerve [66]. However, some patients are not suitable for these treatments, due to the complex pathogenesis of the hearing loss and degree of tissue damage [3] [67]. Many patients, due to the aforementioned changes in the inner ear, show little or no improvement in the hearing levels after introducing on of the rehabilitation methods. Preventing hair cells loss or regenerating hair cells/spiral ganglion neurons using stem cells, gene or drug therapies would be an ideal solution.

Since the first observation of stem cells in the mammalian cochlea, many studies tried to induce regeneration or trans-differentiation of these stem cells using various methods towards their eventual clinical application. Exogenous cell 
transplant has a great potential for SNHL, focusing on the regeneration of the organ of Corti or the cochlear ganglion as main strategies. Nevertheless, it is not enough just to transplant stem cells in the cochlea. The stem cells have to be first induced to differentiate towards neural progenitors and then to sensory neurons using molecular signals. Additionally, in vitro survival and differentiation rates must be examined [66]. Finally, neurotrophic factors must be applied to facilitate the brain-inner ear connection. Furthermore, cochlear environment represents a great challenge for stem cells transplant: the perilymph in the scala tympani and scala vestibule contains low levels of potassium $(10 \mathrm{mEq} / \mathrm{L}$, approximately), while the endolymph in the scala media contains high levels of potassium (144 mEq/L, approximately) [45] [68]. These conditions make any cell type, including stem cells, hard to survive. Additionally, the basilar membrane-rich in collagen-is an obstacle for cellular migration towards the tympanic duct.

Hair cell differentiation is controlled by the transcription factor atonal 1 (Atoh1). Additionally, the transcription factors POU4F3 and GFI1 are also necessary to maintain the hair cell phenotype [23]. The activation of these transcription factors may therefore be key for differentiation of stem cells to become hair cells.

\subsection{Sources of Stem Cells}

Endogenous inner ear stem cells discovered in human fetal cochlea preserve the expression of stem cell markers, such as Nestin, Sox2, Oct4 and Rex1, and can used to generate cochlear hair cells. Under special culture conditions, these stem cells present spiral ganglion neurons and cochlear hair cells characteristics. They also express neuronal differentiation markers (Neurogen 1, Brn3a, b-tubulin III and neurofilament 200) [3]. Hair cell-like cells with mechano-sensitive functioning cilia can be generated from embryonal stem cells and inducible pluripotent stem cells [45].

Embryonic stem cells can differentiate into inner ear progenitors and express inner hair cell phenotype. Embryogenic stem cell-derived neural progenitors can also generate cochlear hair cells and spiral ganglion neurons when manipulated in vitro. Ulfendahl et al. [69] showed a greater capacity of embryonic stem cells to survive in the inner ear. Ronaghi et al. [70] observed that differentiation of embryonic stem cells was dependent on fibroblast growth factor signaling and Atoh1 enhancer; Han et al. [71] demonstrated that embryonic stem cells implanted through cochleostomy survived in the endolymphatic space of the cochlea, and some of the surviving cells differentiated into hair cells by Atoh1 gene transfer.

Furthermore, Hildebrand et al. [72] observed the injected embryonic stem cells near the spiral ligament and stria vascularis-some cases, cells were observed close to the damaged organ of Corti structure-and Hu et al. [73] observed that embryonic dorsal root ganglion neurons had migrated along the in- 
ternal meatus while embryonic stem cells had migrated into the brain stem close to the ventral cochlear nucleus. Additionally, in another study, $\mathrm{Hu}$ et al. [74] found transplanted dorsal root ganglion neurons survived in the scala tympani for a postoperative period ranging from 3 to 10 weeks. Coleman et al. [75] directly delivered mouse embryonic stem cells into the deafened guinea pig cochlea through a xenograft transplantation and observed a small number of viable cells in the scala tympani for up to 4 weeks following transplantation. Corrales et al. [76] injected, through a round window approach, EYFP-expressing embryonic stem cell, and observed (64 - 98 days after injection) a significant increase in neuronal processes near the sensory epithelium. Recently, Chen et al. [77] reported the restoration of auditory evoked responses using embryonic stem cell derived otic progenitors. Although embryonic stem cells (ESCs) have been isolated from humans, their use in research as well as therapeutics is encumbered by ethical considerations [78], and the propensity of ESCs to develop into teratomas [79].

Hematopoietic stem cells obtained from chinchilla bone marrow stroma showed increased neuron and glial cell marker expression under specialized conditions. Some authors also achieved the differentiation of bone-marrow-derived CD113+ stem cells into hair cells-like using growth factors and forcing expression of transcription factor Atoh 1. A study conducted by Revoltella et al. [80] transplanted CD133+ hematopoietic stem cells into deafened mice (made by ototoxic treatment with kanamycin and/or intense noise) and observed a repairing process and stimulation ex novo of morphological recovery in the inner ear.

Elbana et al. [81] mobilized endogenous bone marrow derived stem cells using granulocyte colony stimulating factor (G-CSF) to repair experimentally damaged inner ear hair cells by amikacin injection. Their results were improvement in $50 \%$ of the sensorineural distortion product otoacoustic emission (DPOAE). In addition, the histological examination showed recovery of the organ of Corti. Lang et al. [82] found transplanted bone marrow stem cells -3 to 20 months after transplantation-within the spiral ligament, and some cells expressed immunoreactivity $\mathrm{Na}-\mathrm{K}-\mathrm{ATPase}$, or to the $\mathrm{Na}-\mathrm{K}-\mathrm{Cl}$ transporter.

Mesenchymal stem cells can be induced to differentiate to osteoblasts, chondroblasts, adipocytes, fibroblasts, and skeletal muscle [83]. Aside from differentiation into cells of the mesoderm, multipotent adult progenitor cellsMAPCs-can differentiate into cells with endodermal and neuroectodermal characteristics [84] [85] [86]. Their advantages include high expansion potential, genetic stability, ease of collection, ability to migrate to the injury site, and a strong immunosuppressive property that can be exploited for autologous and heterologous transplants.

Kamiya et al. [58] demonstrated active regeneration of the cochlear fibrocytes after severe focal apoptosis; they transplanted mesenchymal stem cells into the lateral semicircular canal and observed connexin 26 and connexin 30 immunos- 
taining reminiscent of gap junctions. It was observed an increased number of spiral ganglion neurons and some recovering in the ABR thresholds 7 days after ouabain injury and injection of human mesenchymal stem cells, and some expression of neuronal or glial cell marker [46] [87] [88]. In addition to the obvious immunological advantage using autologous stem cells, these cells are not encumbered by ethical considerations. MAPCs have been shown that they survive in the scala tympani up to two weeks [89]. Since MAPCs are multipotent stem cells and capable of becoming hair cells and sensory neurons under the appropriate differentiation conditions, a transplantation of MAPCs into the inner ear may provide a new tool to repair multiple cell types involved in auditory transduction.

Neural stem cells possess little constituent cell renewal and do not regenerate following severe injury [90] but can be recruited to substitute lost neurons if successfully grafted in the inner ear [91]. Clinical applications for neural stem cells have been demonstrated in many animal studies to regenerate or recover a nerve lesion. They are more suitable in the management of spiral ganglion neurons or nerve fibers pathology [45].

Ren et al. [92] observed that neural stem cells differentiated into neurons, migrated and engrafted to the brain after transplantation into a 10-month of age C57BL/6J mice. Iguchi et al. [93] showed histologically that after 4 weeks of transplantation, neural stem cells survived in inner ear and most transplantderived cells had differentiated into glial cells. In another study, $\mathrm{Xu}$ et al. [10] introduced olfactory epithelial neural stem cells in a model of noise-induced hearing loss SD rats (3-week old, weighting $200-250 \mathrm{~g}$ ) and observed a decrease in ABR thresholds by the $5^{\text {th }}$ day post-implantation. Similar study by Pandit et al. [94], found lower hearing thresholds levels in a group of $\mathrm{A} / \mathrm{J}$ mices injected with olfactory stem cells (into the cochlea via lateral wall cochleostomy) compared against animals that received sham injections. However, Fu et al. [95] observed no differences in the click-ABR thresholds. Their study found that neural stem cells survived in normal rat after transplantation via round window but showed no effect on auditory function.

Stem cell-derived auditory-like neurons have also been derived from a variety of sources, such as mouse embryonic stem cells, cochlear stem cells, human embryonic stem cells, and induced pluripotent stem cells [7].

\subsection{How to Insert These Therapies in the Cochlea?}

The cochlea is positioned deep inside of the skull. Even though surgically accessing the cochlea through a cochleostomy or round window approaches have been widely used for cochlear implantation, this surgical process can cause disturbance of the cochlear homeostasis, resulting in residual hearing loss and vertigo. Additionally, the aforementioned techniques are also limited to accessing just the scala tympani in the basal turn of the cochlea [45].

Interesting method proposed by Pinyon et al. that used cochlear implant electrode array as gene electrotransfer platform for delivering plasmid DNA, as an 
alternative strategy for cochlear gene delivery into the cochlea [96]. However, transplantation of stem cells and embryonic neurons into the inner ear has revealed that exogenous cells can survive, migrate, differentiate, and extend neuritic projections in the auditory system of adult mammals [12]. Transplanting stem cells to the cochlea and having them migrate into the Rosenthal's canal is a difficult technique-cochlear structure limits cell migration and surgical access can result in severe hearing loss. Different routes, such as intra-perilymphatic and intra-endolymphatic paths, or using the modiolus/auditory nerve, have been attempted.

Kamiya, in 2015, [97] showed an upregulation of homing receptors CCR2, CXCR4 in culture dish by the treatment of monocyte chemotactic protein-1 (MCP-1) or stromal cell-derived factor-1 (SDF-1). The cells with abundant clustering of chemokine (C-C motif) receptor-2 (CCR2) and C-X-C chemokine receptor type 4 (CXCR4) acquire higher potentials to be attracted by MCP-1 and SDF-1. The pretreated cells were injected into the perilymph via semicircular canal. The MCP-1/SDF-1 secretion from the target site by pre-treatment with 3-nitropropionic acid (3-NP) was responsible for homing the transplanted cells to the target site-spiral ligament and spiral ganglions neurons.

Fetoni et al. [98] introduced adipose-derived stem cells via the round window in guinea pigs (age 3 months, weight 250 - $350 \mathrm{~g}$ ) that were exposed to noise. They measured the ABR thresholds 3 and 7 days after the surgery, with no changes in the auditory function, but observed that the adipose-derived stem cells migrated from the perilymphatic to the endolymphatic compartment. Jang et al. [83] introduced neural-induced human mesenchymal stem cells into the basal turn of the cochlea (into the scala tympani) in deafened guinea pigs (by neomycin injection) and observed an increase in the number of spiral ganglion neurons compared to their control group. Xu et al. [10] introduced olfactory epithelial neural stem cells by drilling a hole at the promontory and localizing the scala tympani; their results suggests migration of the implanted cells to spiral ganglion neurons and decreasing threshold in the ABR.

Iguchi et al. [99] injected transplant-derived cells through lateral semicircular canal and cochlear lateral wall. After 2 weeks, showed elevation of ABR thresholds by less than $10 \mathrm{~dB}$ SPL in the lateral semicircular canal injection groupwhile the cochlear lateral wall injection resulted in considerable hearing loss. In a recent multinational study, named NANOCI, researchers tried to create a gapless interface between auditory nerve fibers and cochlear implant. They generated a modified nano-cochlear implant electrode array that was inserted into the scala tympani and resulted in a neurotrophin-induced attraction of neurites, which led to lower stimulation thresholds and reduction in required stimulation energy [100].

\section{Conclusions}

Age-related hearing loss is a common condition with possible significant public 
health implications. Various changes have been identified within the cochlea in association with ARHL including deterioration of the organ of Corti, loss of spiral ganglion and auditory nerve fiber, and anatomical changes in the cochlear lateral wall. The etiology of ARHL is multifactorial with evidence of oxidative damage with mutation of the mitochondrial genome, reduced defense mechanisms, genetic factors, and exogenous factors including ototoxins and noise exposure.

Although there is no currently widely accepted treatment or preventive measure for ARHL, a number of treatments have shown promise in the literature, and the stem cells therapy seems to be a viable option for the near future.

\section{Conflicts of Interest}

The authors declare no conflicts of interest regarding the publication of this paper.

\section{Funding}

This study was funded by National Institute on Deafness and Other Communication Disorders (U24 DC011968), International Hearing Foundation, Starkey Hearing Foundation, Lions 5M International, and Coordenação de Aperfeiçoamento de Pessoal de Nível Superior (CAPES, code 001).

\section{References}

[1] Qian, Z.J., Chang, P.D., Moonis, G. and Lalwani, A.K. (2017) A Novel Method of Quantifying Brain Atrophy with Age-Related Hearing Loss. NeuroImage: Clinical, 16, 205-209. https://doi.org/10.1016/j.nicl.2017.07.021

[2] Thomson, R.S., Auduong, P., Miller, A.T. and Gurgel, R.K. (2017) Hearing Loss as a Risk Factor for Dementia: A Systematic Review. Laryngoscope Investigative Otolaryngology, 16, 69-79. https://doi.org/10.1002/lio2.65

[3] Almeida-Branco, M.S., Cabrera, S. and Lopez-Escamez, J.A. (2015) Perspectives for the Treatment of Sensorineural Hearing Loss by Cellular Regeneration of the Inner Ear. Acta Otorrinolaringológica Española, 66, 286-295. https://doi.org/10.1016/j.otorri.2014.07.009

[4] Yueh, B., Shapiro, N., MacLea, C.H. and Shekelle, P.G. (2003) Screening and Management of Adult Hearing Loss in Primary Care: Scientific Review. JAMA, 289, 1976-1985. https://doi.org/10.1001/jama.289.15.1976

[5] Cruickshanks, K.J., Wiley, T.L., Tweed, T.S., et al. (1998) Prevalence of Hearing Loss in Older Adults in Beaver Dam, Wisconsin. The Epidemiology of Hearing Loss Study. American Journal of Epidemiology, 148, 879-886. https://doi.org/10.1093/oxfordjournals.aje.a009713

[6] Seidman, M.D. (2000) Effect of Dietary Restriction and Antioxidants on Presbycusis. Laryngoscope, 110, 727-738.

https://doi.org/10.1097/00005537-200005000-00003

[7] Gillespie, L.N., Richardson, R.T., Nayagam, B.A. and Wise, A.K. (2014) Treating Hearing Disorders with Cell and Gene Therapy. Journal of Neural Engineering, 11, 065001. https://doi.org/10.1088/1741-2560/11/6/065001

[8] Tanigawa, T., Shibata, R., Ouchi, N., et al. (2014) Adiponectin Deficiency Exacer- 
bates Age-Related Hearing Impairment. Cell Death \& Disease, 5, e1189. https://doi.org/10.1038/cddis.2014.140

[9] Melgar-Rojas, P., Alvarado, J.C., Fuentes-Santamaría, V. and Juiz, J.M. (2015) Free Radicals in ENT Pathology, Oxidative Stress in Applied Basic Research and Clinical Practice. Springer International Publishing, Switzerland.

[10] Xu, Y.P., Shan, X.D., Liu, Y.Y., et al. (2016) Olfactory Epithelium Neural Stem Cell Implantation Restores Noise-Induced Hearing Loss in Rats. Neuroscience Letters, 616, 19-25. https://doi.org/10.1016/j.neulet.2016.01.016

[11] Schuknecht, H.F. (1964) Further Observations on the Pathology of Presbycusis. Archives of Otolaryngology, 80, 369-382. https://doi.org/10.1001/archotol.1964.00750040381003

[12] Hu, Z. and Ulfendahl, M. (2006) Cell Replacement Therapy in the Inner Ear. Stem Cells and Development, 15, 449-459. https://doi.org/10.1089/scd.2006.15.449

[13] Sousounis, K., Baddour, J.A. and Tsonis, P.A. (2014) Aging and Regeneration in Vertebrates. Current Topics in Developmental Biology, 108, 217-246. https://doi.org/10.1016/B978-0-12-391498-9.00008-5

[14] Uzhachenko, R., Boyd, K., Olivares-Villagomez, D., et al. (2017) Mitochondrial Protein Fus1/Tusc2 in Premature Aging and Age-Related Pathologies: Critical Roles of Calcium and Energy Homeostasis. Aging, 9, 627-649.

https://doi.org/10.18632/aging.101213

[15] Falah, M., Farhadi, M., Kamrava, S.K., et al. (2017) Association of Genetic Variations in the Mitochondrial DNA Control Region with Presbycusis. Clinical Interventions in Aging, 12, 459-465. https://doi.org/10.2147/CIA.S123278

[16] Cooney, R.V., Hardwood, P.J., Franke, A.A., et al. (1995) Products of Gamma-Tocopherol Reaction with $\mathrm{NO}_{2}$ and Their Formation in Rat Insulinoma (RINm5F) Cells. Free Radical Biology \& Medicine, 19, 259-269. https://doi.org/10.1016/0891-5849(95)00019-T

[17] Inai, S., Watanabe, K. and Okubo, K. (2012) Inducible Nitric Oxide Synthase Participates in Cochlear Damage after Acoustic Stimulation in Guinea Pigs. Journal of Nippon Medical School, 79, 121-128. https://doi.org/10.1272/jnms.79.121

[18] Luna, M.C., Ferrario, A., Wong, S., Fisher, A.M. and Gomer, C.J. (2000) Photodynamic Therapy-Mediated Oxidative Stress as a Molecular Switch for the Temporal Expression of Genes Ligated to the Human Heat Shock Promoter. Cancer Research, 60, 1637-1644.

[19] Gosslau, A., Ruoff, P., Mohsenzadeh, S., Hobohm, U. and Rensing, L. (2001) Heat Shock and Oxidative Stress-Induced Exposure of Hydrophobic Protein Domains as Common Signal in the Induction of hsp68. The Journal of Biological Chemistry, 276, 1814-1821. https://doi.org/10.1074/jbc.M008280200

[20] Smolka, M.B., Zoppi, C.C., Alves, A.A., et al. (2000) HSP72 as a Complementary Protection against Oxidative Stress Induced by Exercise in the Soleus Muscle of Rats. American Journal of Physiology-Regulatory, Integrative and Comparative Physiology, 279, R1539-R1545. https://doi.org/10.1152/ajpregu.2000.279.5.R1539

[21] Bernstein, S.L., Liu, A.M.H., Hansen, B.C. and Somiari, R.I. (2000) Heat Shock Cognate-70 Gene Expression Declines during Normal Aging of Primate Retina. Investigative Ophthalmology \& Visual Science, 41, 2857-2862.

[22] Fargnoli, J., Kunisada, T., Fornace Jr., A.J., Schneider, E.L. and Holbrook, N.J. (1990) Decreased Expression of Heat Shock Protein 70 mRNA and Protein after Heat Treatment in Cells of Aged Rats. Proceedings of the National Academy of Sciences of the United States of America, 87, 846-850. 
https://doi.org/10.1073/pnas.87.2.846

[23] Müller, U. and Barr-Gillespie, P.G. (2015) New Treatment Options for Hearing Loss. Nature Reviews Drug Discovery, 14, 346-365. https://doi.org/10.1038/nrd4533

[24] Fransen, E., Topsakal, V., Hendrickx, J.J., et al. (2008) Occupational Noise, Smoking, and a High Body Mass Index Are Risk Factors for Age-Related Hearing Impairment and Moderate Alcohol Consumption Is Protective: A European Population-Based Multicenter Study. Journal of the Association for Research in Otolaryngology, 9, 264-276. https://doi.org/10.1007/s10162-008-0123-1

[25] Popelka, M.M., Cruickshanks, K.J., Wiley, T.L., et al. (2000) Moderate Alcohol Consumption and Hearing Loss: A Protective Effect. Journal of the American Geriatrics Society, 48, 1273-1278. https://doi.org/10.1111/j.1532-5415.2000.tb02601.x

[26] Yang, H., Xiong, H., Huang, Q., et al. (2013) Compromised Potassium Recycling in the Cochlea Contributes to Conservation of Endocochlear Potential in a Mouse Model of Age-Related Hearing Loss. Neuroscience Letters, 555, 97-101. https://doi.org/10.1016/j.neulet.2013.09.028

[27] Altschuler, R.A., Dolan, D.F., Halsey, K., et al. (2015) Age-Related Changes in Auditory Nerve-Inner Hair Cell Connections, Hair Cell Numbers, Auditory Brain Stem Response and Gap Detection in UM-HET4 Mice. Neuroscience, 292, 22-33. https://doi.org/10.1016/j.neuroscience.2015.01.068

[28] Juhn, S.K., Hunter, B.A. and Odland, R.M. (2001) Blood-Labyrinth Barrier and Fluid Dynamics of the Inner Ear. The International Tinnitus Journal, 7, 72-83.

[29] Ichimiya, I., Suzuki, M. and Mogi, G. (2000) Age-Related Changes in the Murine Cochlear Lateral Wall. Hearing Research, 139, 116-122. https://doi.org/10.1016/S0378-5955(99)00170-7

[30] Schmidt, R.S. (1963) Independence of the Endovestibular Potential in Homeotherms. The Journal of General Physiology, 47, 371-378.

https://doi.org/10.1085/jgp.47.2.371

[31] Cotrina, M.L., Gao, Q., Lin, J.H. and Nedergaard, M. (2001) Expression and Function of Astrocytic Gap Junctions in Aging. Brain Research, 901, 55-61. https://doi.org/10.1016/S0006-8993(01)02258-2

[32] Wu, T. and Marcus, D.C. (2003) Age-Related Changes in Cochlear Endolymphatic Potassium and Potential in CD-1 and CBA/CaJ Mice. Journal of the Association for Research in Otolaryngology, 4, 353-362. https://doi.org/10.1007/s10162-002-3026-6

[33] Sha, S.H., Kanicki, A., Dootz, G., et al. (2008) Age-Related Auditory Pathology in the CBA/J Mouse. Hearing Research, 243, 87-94. https://doi.org/10.1016/j.heares.2008.06.001

[34] Nadol Jr., J.B. (1979) Electron Microscopic Findings in Presbycusis Degeneration of the Basal Turn of the Human Cochlea. Otolaryngology-Head and Neck Surgery, 87, 818-836. https://doi.org/10.1177/019459987908700617

[35] Bohner, B., Gruner, M.M. and Harding, G.W. (1990) Morphological Correlates of Aging in the Chinchilla Cochlea. Hearing Research, 48, 79-91. https://doi.org/10.1016/0378-5955(90)90200-9

[36] Mizuta, K., Nozawa, O., Morita, H. and Hoshino, T. (1993) Scanning Electron Microscopy of Age-Related Changes in the C57BL/6J Mouse Cochlea. Scanning Microscopy, 7, 889-896.

[37] Adam, J. and Schulte, B.A. (1997) Histopathological Observations of the Ageing Gerbil Cochlea. Hearing Research, 104, 101-111. https://doi.org/10.1016/S0378-5955(96)00184-0 
[38] Ingham, N.J., Comis, S.D. and Withington, D.J. (1999) Hair Cell Loss in the Aged Guinea Pig Cochlea. Acta Oto-Laryngologica, 119, 42-47. https://doi.org/10.1080/00016489950181918

[39] Meyer zum Gottesberge, A.M., Felix, H., Reuter, A. and Weiher, H. (2001) Ultrastructural and Physiological Defects in the Cochlea of the Mpv17 Mouse Strain. A Comparison between Young and Old Adult Animals. Hearing Research, 156, 69-80. https://doi.org/10.1016/S0378-5955(01)00268-4

[40] Scholtz, A.W., Kammen-Jolly, K.E., Felder, E., Hussl, B., Rask-Andersen, H. and Schrott-Fischer, A.S. (2001) Selective Aspects of Human Pathology in High-Tone Hearing Loss of the Aging Inner Ear. Hearing Research, 157, 77-86. https://doi.org/10.1016/S0378-5955(01)00279-9

[41] Johnson, K.R., Tian, C., Gagnon, L.H., Jiang, H., Ding, D. and Salvi, R. (2017) Effects of Cdh23 Single Nucleotide Substitutions on Age-Related Hearing Loss in C57BL/6 and 129S1/Sv Mice and Comparisons with Congenic Strains. Scientific Reports, 7, Article No. 44450.

[42] Kane, K.L., Longo-Guess, C.M., Gagnon, L.H., Ding, D., Salvi, R.J. and Johnson, K.R. (2012) Genetic Background Effects on Age-Related Hearing Loss Associated with Cdh23 Variants in Mice. Hearing Research, 283, 80-88.

https://doi.org/10.1016/j.heares.2011.11.007

[43] Turner, J.G., Parrish, J.L., Zuiderveld, L., et al. (2013) Acoustic Experience Alters the Aged Auditory System. Ear and Hearing, 34, 151-159. https://doi.org/10.1097/AUD.0b013e318269ca5b

[44] Vlajkovic, S.M., Guo, C.X., Telang, R., et al. (2011) Adenosine Kinase Inhibition in the Cochlea Delays the Onset of Age-Related Hearing Loss. Experimental Gerontology, 46, 905-914. https://doi.org/10.1016/j.exger.2011.08.001

[45] Park, Y.H. (2015) Stem Cell Therapy for Sensorineural Hearing Loss, Still Alive? Journal of Audiology \& Otology, 19, 63-67. https://doi.org/10.7874/jao.2015.19.2.63

[46] Matsuoka, A.J., Kondo, T., Miyamoto, R.T. and Hashino, E. (2007) Enhanced Survival of Bone-Marrow-Derived Pluripotent Stem Cells in an Animal Model of Auditory Neuropathy. Laryngoscope, 117, 1629-1635. https://doi.org/10.1097/MLG.0b013e31806bf282

[47] Kusunoki, T., Cureoglu, S., Schachern, P.A., Baba, K., Kariya, S. and Paparella, M.M. (2004) Age-Related Histopathologic Changes in the Human Cochlea: A Temporal Bone Study. Otolaryngology_Head and Neck Surgery, 131, 897-903. https://doi.org/10.1016/j.otohns.2004.05.022

[48] Chen, P. and Segil, N. (1999) p2 $7^{\mathrm{Kip} 1}$ Links Cell Proliferation to Morphogenesis in the Developing Organ of Corti. Development, 126, 1581-1590.

[49] Lowenheim, H., Furness, D.N., Kil, J., et al. (1999) Gene Disruption of p27 ${ }^{\text {Kip1 }}$ Allows Cell Proliferation in the Postnatal and Adult Organ of Corti. Proceedings of the National Academy of Sciences of the United States of America, 96, 4084-4088. https://doi.org/10.1073/pnas.96.7.4084

[50] Weber, T., Corbett, M.K., Chow, L.M., Valentine, M.B., Baker, S.J. and Zuo, J. (2008) Rapid Cell-Cycle Reentry and Cell Death after Acute Inactivation of the Retinoblastoma Gene Product in Postnatal Cochlear Hair Cells. Proceedings of the National Academy of Sciences of the United States of America, 105, 781-785. https://doi.org/10.1073/pnas.0708061105

[51] Yu, Y., Weber, T., Yamashita, T., et al. (2010) In Vivo Proliferation of Postmitotic Cochlear Supporting Cells by Acute Ablation of the Retinoblastoma Protein in Neonatal Mice. Journal of Neuroscience, 30, 5927-5936. 
https://doi.org/10.1523/JNEUROSCI.5989-09.2010

[52] Rocha-Sanchez, S.M., Scheetz, L.R., Contreras, M., et al. (2011) Mature Mice Lacking $R b h / \mathrm{p} 130$ Gene Have Supernumerary Inner Ear Hair Cells and Supporting Cells. Journal of Neuroscience, 31, 8883-8893. https://doi.org/10.1523/JNEUROSCI.5821-10.2011

[53] Laine, H., Doetzlhofer, A., Mantela, J., et al. (2007) p19 ${ }^{\text {Ink4d }}$ and p21 Cip1 Collaborate to Maintain the Postmitotic State of Auditory Hair Cells, Their Codeletion Leading to DNA Damage and p53-Mediated Apoptosis. Journal of Neuroscience, 27, 1434-1444. https://doi.org/10.1523/JNEUROSCI.4956-06.2007

[54] Chai, R., Kuo, B., Wang, T., et al. (2012) Wnt Signaling Induces Proliferation of Sensory Precursors in the Postnatal Mouse Cochlea. Proceedings of the National Academy of Sciences of the United States of America, 109, 8167-8172.

https://doi.org/10.1073/pnas.1202774109

[55] Kelly, M.C., Chang, Q., Pan, A., Lin, X. and Chen, P. (2012) Atoh1 Directs the Formation of Sensory Mosaics and Induces Cell Proliferation in the Postnatal Mammalian Cochlea in Vivo. Journal of Neuroscience, 32, 6699-6710. https://doi.org/10.1523/JNEUROSCI.5420-11.2012

[56] Xia, M.Y., Zhao, X.Y., Huang, Q.L., et al. (2017) Activation of Wnt/ $\beta$-Catenin Signaling by Lithium Chloride Attenuates D-Galactose-Induced Neurodegeneration in the Auditory Cortex of a Rat Model of Aging. FEBS Open Bio, 7, 759-776. https://doi.org/10.1002/2211-5463.12220

[57] Hequembourg, S. and Liberman, M.C. (2001) Spiral Ligament Pathology: A Major Aspect of Age-Related Cochlear Degeneration in C57BL/6 Mice. Journal of the Association for Research in Otolaryngology, 2, 118-129. https://doi.org/10.1007/s101620010075

[58] Kamiya, K., Fujinami, Y., Hoya, N., et al. (2007) Mesenchymal Stem Cell Transplantation Accelerates Hearing Recovery through the Repair of Injured Cochlear Fibrocytes. The American Journal of Pathology, 171, 214-226. https://doi.org/10.2353/ajpath.2007.060948

[59] Thomopoulos, G.N., Spicer, S., Gratton, M.A. and Schulte, B.A. (1997) Age-Related Thickening of Basement Membrane in Stria Vascularis Capillaries. Hearing Research, 111, 31-41. https://doi.org/10.1016/S0378-5955(97)00080-4

[60] Suzuki, T., Nomoto, Y., Nakagawa, T., et al. (2006) Age-Dependent Degeneration of the Stria Vascularis in Human Cochleae. Laryngoscope, 116, 1846-1850. https://doi.org/10.1097/01.mlg.0000234940.33569.39

[61] Picciotti, P., Torsello, A., Wolf, F.I., Paludetti, G., Gaetani, E. and Pola, R. (2004) Age-Dependent Modifications of Expression Level of VEGF and Its Receptors in the Inner Ear. Experimental Gerontology, 39, 1253-1258.

https://doi.org/10.1016/j.exger.2004.06.003

[62] Yang, D., Zhang, J.N. and Zhou, H.F. (2014) Endothelial Progenitor Cells in Patients with Age-Related Hearing Loss. American Journal of Otolaryngology, 35, 695-698. https://doi.org/10.1016/j.amjoto.2014.08.005

[63] Rak, K., Völker, J., Jürgens, L., et al. (2015) Cochlear Nucleus Whole Mount Explants Promote the Differentiation of Neuronal Stem Cells from the Cochlear Nucleus in Co-Culture Experiments. Brain Research, 1616, 58-70. https://doi.org/10.1016/j.brainres.2015.04.055

[64] Akil, O., Sun, Y., Vijayakumar, S., et al. (2015) Spiral Ganglion Degeneration and Hearing Loss as a Consequence of Satellite Cell Death in Saposin B-Deficient Mice. Journal of Neuroscience, 35, 3263-3275. 
https://doi.org/10.1523/JNEUROSCI.3920-13.2015

[65] Tang, X., Zhu, X., Ding, B., Walton, J.P., Frisina, R.D. and Su, J. (2014) Age-Related Hearing Loss: GABA, Nicotinic Acetylcholine and NMDA Receptor Expression Changes in Spiral Ganglion Neurons of the Mouse. Neuroscience, 259, 184-193. https://doi.org/10.1016/j.neuroscience.2013.11.058

[66] Altschuler, R.A., O’Shea, K.S. and Miller, J.M. (2008) Stem Cell Transplantation for Auditory Nerve Replacement. Hearing Research, 242, 110-116. https://doi.org/10.1016/j.heares.2008.06.004

[67] Revuelta, M., Santaolalla, F., Arteaga, O., Alvarez, A., Sánchez-Del-Rey, A. and Hilario, E. (2017) Recent Advances in Cochlear Hair Cell Regeneration-A Promising Opportunity for the Treatment of Age-Related Hearing Loss. Ageing Research Reviews, 36, 149-155. https://doi.org/10.1016/j.arr.2017.04.002

[68] Nakagawa, T. (2014) Strategies for Developing Novel Therapeutics for Sensorineural Hearing Loss. Frontiers in Pharmacology, 5, 206. https://doi.org/10.3389/fphar.2014.00206

[69] Ulfendahl, M., Hu, Z., Olivius, P., Duan, M. and Wei, D. (2007) A Cell Therapy Approach to Substitute Neural Elements in the Inner Ear. Physiology \& Behavior, 92, 75-79. https://doi.org/10.1016/j.physbeh.2007.05.054

[70] Ronaghi, M., Nasr, M., Ealy, M., et al. (2014) Inner Ear Hair Cell-Like Cells from Human Embryonic Stem Cells. Stem Cells and Development, 23, 1275-1284. https://doi.org/10.1089/scd.2014.0033

[71] Han, Z., Yang, J.M., Chi, F.L., et al. (2010) Survival and Fate of Transplanted Embryonic Neural Stem Cells by Atoh1 Gene Transfer in Guinea Pigs Cochlea. Neuroreport, 21, 490-496. https://doi.org/10.1097/WNR.0b013e3283383410

[72] Hildebrand, M.S., Dahl, H.H., Hardman, J., Coleman, B., Shepherd, R.K. and de Silva, M.G. (2005) Survival of Partially Differentiated Mouse Embryonic Stem Cells in the Scala Media of the Guinea Pig Cochlea. Journal of the Association for Research in Otolaryngology, 6, 341-354. https://doi.org/10.1007/s10162-005-0012-9

[73] Hu, Z., Ulfendahl, M. and Olivius, N.P. (2004) Central Migration of Neuronal Tissue and Embryonic Stem Cells Following Transplantation along the Adult Auditory Nerve. Brain Research, 1026, 68-73. https://doi.org/10.1016/j.brainres.2004.08.013

[74] Hu, Z., Ulfendahl, M. and Olivius, N.P. (2004) Survival of Neuronal Tissue Following Xenograft Implantation into the Adult Rat Inner Ear. Experimental Neurology, 185, 7-14. https://doi.org/10.1016/j.expneurol.2003.09.013

[75] Coleman, B., Hardman, J., Coco, A., et al. (2006) Fate of Embryonic Stem Cells Transplanted into the Deafened Mammalian Cochlea. Cell Transplantation, 15, 369-380. https://doi.org/10.3727/000000006783981819

[76] Corrales, C.E., Pan, L., Li, H., Liberman, M.C., Heller, S. and Edge, A.S. (2006) Engraftment and Differentiation of Embryonic Stem Cell-Derived Neural Progenitor Cells in the Cochlear Nerve Trunk: Growth of Processes into the Organ of Corti. Journal of Neurobiology, 66, 1489-1500. https://doi.org/10.1002/neu.20310

[77] Chen, W., Jongkamonwiwat, N., Abbas, L., et al. (2012) Restoration of Auditory Evoked Responses by Human ES-Cell-Derived Otic Progenitors. Nature, 490, 278282. https://doi.org/10.1038/nature11415

[78] Frankel, M.S. (2000) In Search of Stem Cell Policy. Science, 287, 1397. https://doi.org/10.1126/science.287.5457.1397

[79] Gunewardene, N., Bergen, N.V., Crombie, D., Needham, K., Dottori, M. and Nayagam, B.A. (2014) Directing Human Induced Pluripotent Stem Cells into a Neuro- 
sensory Lineage for Auditory Neuron Replacement. BioResearch Open Access, 3, 162-175. https://doi.org/10.1089/biores.2014.0019

[80] Revoltella, R.P., Papini, S., Rosellini, A., et al. (2008) Cochlear Repair by Transplantation of Human Cord Blood CD133+ Cells to Nod-Scid Mice Made Deaf with Kanamycin and Noise. Cell Transplantation, 17, 665-678.

https://doi.org/10.3727/096368908786092685

[81] Elbana, A.M., Abdel-Salam, S., Morad, G.M. and Omran, A.A. (2015) Role of Endogenous Bone Marrow Stem Cells Mobilization in Repair of Damaged Inner Ear in Rats. International Journal of Stem Cells, 8, 146-154. https://doi.org/10.15283/ijsc.2015.8.2.146

[82] Lang, H., Ebihara, Y., Schmiedt, R.A., et al. (2006) Contribution of Bone Marrow Hematopoietic Stem Cells to Adult Mouse Inner Ear: Mesenchymal Cells and Fibrocytes. Journal of Comparative Neurology, 496, 187-201.

https://doi.org/10.1002/cne.20929

[83] Jang, S., Cho, H.H., Kim, S.H., et al. (2015) Neural-Induced Human Mesenchymal Stem Cells Promote Cochlear Cell Regeneration in Deaf Guinea Pigs. Clinical and Experimental Otorhinolaryngology, 8, 83-91.

https://doi.org/10.3342/ceo.2015.8.2.83

[84] Reyes, M. and Verfaillie, C.M. (2001) Characterization of Multipotent Adult Progenitor Cells, a Subpopulation of Mesenchymal Stem Cells. Annals of the New York Academy of Sciences, 938, 231-235. https://doi.org/10.1111/j.1749-6632.2001.tb03593.x

[85] Jiang, Y., Jahagirdar, B.N., Reinhardt, R.L., et al. (2002) Pluripotency of Mesenchymal Stem Cells Derived from Adult Marrow. Nature, 418, 41-49. https://doi.org/10.1038/nature00870

[86] Schwartz, R.E., Reyes, M., Koodie, L., et al. (2002) Multipotent Adult Progenitor Cells from Bone Marrow Differentiate into Functional Hepatocyte-Like Cells. Journal of Clinical Investigation, 109, 1291-1302. https://doi.org/10.1172/JCI0215182

[87] Cho, Y.B., Cho, H.H., Jang, S., Jeong, H.S. and Park, J.S. (2011) Transplantation of Neural Differentiated Human Mesenchymal Stem Cells into the Cochlea of an Auditory-Neuropathy Guinea Pig Model. Journal of Korean Medical Science, 26, 492-498. https://doi.org/10.3346/jkms.2011.26.4.492

[88] Naito, Y., Nakamura, T., Nakagawa, T., et al. (2004) Transplantation of Bone Marrow Stromal Cells into the Cochlea of Chinchillas. NeuroReport, 15, 1-4. https://doi.org/10.1097/00001756-200401190-00001

[89] Jurney, W.M., Oh, S., Keene, C.D., et al. (2003) Survival and Distribution of Adult-Derived Stem Cells Transplanted into the Adult Mouse Inner Ear. In: Santi, P.A., Ed., Abstracts of the 26th Annual Midwinter Research Meeting, Association for Research in Otolaryngology, Daytona Beach, FL, 22-27 February 2003, 262.

[90] Hu, Z., Wei, D., Johansson, C.B., et al. (2005) Survival and Neural Differentiation of Adult Neural Stem Cells Transplanted into the Mature Inner Ear. Experimental Cell Research, 302, 40-47. https://doi.org/10.1016/j.yexcr.2004.08.023

[91] Ito, J., Kojima, K. and Kawaguchi, S. (2001) Survival of Neural Stem Cells in the Cochlea. Acta Oto-Laryngologica, 121, 140-142. https://doi.org/10.1080/000164801300043226

[92] Ren, H., Chen, J., Wang, Y., Zhang, S. and Zhang, B. (2013) Intracerebral Neural Stem Cell Transplantation Improved the Auditory of Mice with Presbycusis. International Journal of Clinical and Experimental Pathology, 6, 230-241.

[93] Iguchi, F., Nakagawa, T., Tateya, I., et al. (2003) Trophic Support of Mouse Inner 
Ear by Neural Stem Cell Transplantation. NeuroReport, 14, 77-80. https://doi.org/10.1097/00001756-200301200-00015

[94] Pandit, S.R., Sullivan, J.M., Egger, V., Borecki, A.A. and Oleskevich, S. (2011) Functional Effects of Adult Human Olfactory Stem Cells on Early-Onset Sensorineural Hearing Loss. Stem Cells, 29, 670-677. https://doi.org/10.1002/stem.609

[95] Fu, Y., Wang, S., Liu, Y., et al. (2009) Study on Neural Stem Cell Transplantation into Natural Rat Cochlea via Round Window. American Journal of Otolaryngology, 30, 8-16. https://doi.org/10.1016/j.amjoto.2007.12.006

[96] Pinyon, J.L., Tadros, S.F., Froud, K.E., et al. (2014) Close-Field Electroporation Gene Delivery Using the Cochlear Implant Electrode Array Enhances the Bionic Ear. Science Translational Medicine, 6, 233 ra54.

https://doi.org/10.1126/scitranslmed.3008177

[97] Kamiya, K. (2015) Inner Ear Cell Therapy Targeting Hereditary Deafness by Activation of Stem Cell Homing Factors. Frontiers in Pharmacology, 6, 2. https://doi.org/10.3389/fphar.2015.00002

[98] Fetoni, A.R., Lattanzi, W., Eramo, S.L.M., et al. (2014) Grafting and Early Expression of Growth Factors from Adipose-Derived Stem Cells Transplanted into the Cochlea, in a Guinea Pig Model of Acoustic Trauma. Frontiers in Cellular Neuroscience, 8, 334. https://doi.org/10.3389/fncel.2014.00334

[99] Iguchi, F., Nakagawa, T., Tateya, I., et al. (2004) Surgical Techniques for Cell Transplantation into the Mouse Cochlea. Acta Oto-Laryngologica. Supplementum, No. $551,43-47$.

[100] Senn, P., Roccio, M., Hahnewald, S., et al. (2017) NANOCI-Nanotechnology Based Cochlear Implant with Gapless Interface to Auditory Neurons. Otology \& Neurotology, 38, e224-e231. https://doi.org/10.1097/MAO.0000000000001439 